\title{
COMPARACIÓN DEL EFECTO ANTIBACTERIANO DE UN EXTRACTO ETANÓLICO DE PROPÓLEO A DOS CONCENTRACIONES Y DEL PARAMONOCLOROFENOL ALCANFORADO FRENTE A Enterococcus Faecalis Y Fusobacterium Nucleatum
}

\section{COMPARISON BETWEEN THE ANTIBACTERIAL EFFECTS OF TWO CONCENTRATIONS \\ OF AN ETHANOLIC EXTRACT OF PROPOLIS AND CAMPHORATED PARAMONOCHLOROPHENOL VERSUS Enterococcus Faecalis \\ AND Fusobacterium Nucleatum \\ José Diego Torres Mantilla \\ diegotm548@gmail.com \\ ORCID: 0000-0003-4733-3489}

\section{RESUMEN}

Objetivo: Comparar el efecto antibacteriano in vitro de un extracto etanólico de propóleo a dos concentraciones frente a Enterococcus faecalis ATCC: 29212 y Fusobacterium nucleatum ATCC: 25586 con el paramonoclorofenol alcanforado (PMCFA). Materiales y método: Se incluyeron dos grupos de 15 placas Petri con cepas activadas de Enterococcus faecalis y Fusobacterium nucleatum. Se elaboró un extracto etanólico a partir de propóleo (EEP), proveniente de la provincia de Oxapampa (Perú), y se diluyó a concentraciones del $20 \%$ y el $30 \%$. Se comparó su efecto antibacteriano frente al PMCFA, usando clorhexidina al $2 \%$ como control positivo y agua destilada como control negativo; mediante el método de Kirby-Bauer, en un periodo de 7 días para Fusobacterium nucleatum y 24 y 48 horas para Enterococcus faecalis. Se realizó el análisis estadístico mediante el programa SPSS versión 21. Resultados: Frente a Enterococcus faecalis se obtuvieron halos de $10,32 \mathrm{~mm}, 14,23 \mathrm{~mm}$ y $9,10 \mathrm{~mm}$ a las
24 horas y halos de $11 \mathrm{~mm}, 14,96 \mathrm{~mm}$ y $8,94 \mathrm{~mm}$ a las 48 horas, para las concentraciones de EEP al $20 \%$, el $30 \%$ y el PMCFA, respectivamente. Por su parte, frente a Fusobacterium nucleatum, halos de $18,89 \mathrm{~mm}, 23,17 \mathrm{~mm}$ y $13,50 \mathrm{~mm}$ para las concentraciones al $20 \%$, el $30 \%$ y el PMCFA, respectivamente. Conclusiones: El extracto etanólico elaborado a partir de propóleo de Oxapampa mostró efecto antibacteriano a una concentración del $20 \%$ y el $30 \%$, que fue significativamente mayor al del PMCFA, frente a cepas activadas de Enterococcus faecalis y Fusobacterium nucleatum.

Palabras clave: extracto etanólico, propóleo, paramonoclorofenol alcanforado, Enterococcus faecalis, Fusobacterium nucleatum

\section{ABSTRACT}

Objective: To compare the antibacterial effect of two concentrations of an ethanolic extract of propolis (EEP) with that of camphorated paramonochlorophenol

Citar como: Torres-Mantilla JD. Comparación del efecto antibacteriano de un extracto etanólico de propóleo a dos concentraciones y del paramonoclorofenol alcanforado frente a Enterococcus faecalis y Fusobacterium nucleatum. Rev Cient Odontol (Lima). 2019; 7 (1): 53-65. 
(CPMC) in Enterococcus faecalis ATCC: 29212 and Fusobacterium nucleatum ATCC: 25586. Material and methods: Two groups of 15 petri plates each, containing activated strains of Enterococcus faecalis and Fusobacterium nucleatum were included in the study. The EEP was prepared using Peruvian propolis from the province of Oxapampa diluted to $20 \%$ and $30 \%$ of the original concentration. The antibacterial effect of both extracts was compared to CPMC using the KirbyBauer disk diffusion method of 07 days for Fusobacterium nucleatum and 24 and 48 hours for Enterococcus faecalis. Statistical analysis was performed using the SPSS program version 21. Results: Inhibitory diameters of $10.32 \mathrm{~mm}$ for $20 \%$ EEP, $14.23 \mathrm{~mm}$ for $30 \%$ EEP and 9.10 $\mathrm{mm}$ for CPMC were obtained for Enterococcus faecalis at 24 hours, being 11 $\mathrm{mm}$ for $20 \% \mathrm{EEP}, 14.96 \mathrm{~mm}$ for $30 \%$ EEP and $8.94 \mathrm{~mm}$ for CPMC at 48 hours. For Fusobacterium nucleatum, the inhibitory diameters were $18.89 \mathrm{~mm}$ for 20\% EEP, $23.17 \mathrm{~mm}$ for $30 \%$ EEP and $13.50 \mathrm{~mm}$ for CPMC at 7 days. Conclusions: The EEP elaborated from Oxapampa Propolis showed antibacterial effects at concentrations of $20 \%$ and $30 \%$, which were significantly higher than those of CPMC in activated strains of Enterococcus faecalis and Fusobacterium nucleatum.

Keywords: ethanolic extract, propolis, camphorated paramonochlorophenol, Enterococcus faecalis, Fusobacterium nucleatum

\section{INTRODUCCIÓN}

El sistema de conductos radiculares y el tejido pulpar presentan características específicas en cuanto a su anatomía e histología, lo que establece la necesidad de un complejo proceso para el tratamiento de sus patologías $\left(^{1,2}\right)$. A pesar de que los avances tecnológicos nos permiten una conformación cercana a los objetivos biológicos ideales de asepsia, así como la determinación más exacta de límites y la localización de conductos accesorios, la complejidad real del sistema de conductos determina la potencial remanencia de tejido y componentes bacterianos una vez finalizado el tratamiento endodóntico ${ }^{(2-4)}$.

Diversos estudios han determinado la prevalencia de bacterias anaerobias estrictas y facultativas en infecciones periapicales y pulpas no vitales $(5,6,7)$; de modo que, en estos casos, luego de realizada la adecuada conformación e irrigación del conducto radicular, estas bacterias pueden persistir dentro de los túbulos dentinarios y de las múltiples ramificaciones del sistema de conductos $\left.{ }^{4}\right)$. En tal sentido, se ha comprobado la presencia del Enterococcus faecalis en numerosas infecciones endodónticas, además de su alta patogenicidad $(5,6)$; así como la presencia del Fusobacterium nucleatum, que evidencia un alto poder de coagregación dentro del biofilm endodóntico $(6,7)$.

Actualmente, se investigan alternativas para la medicación intraconducto, que contemplan elementos sintetizados en laboratorio y sustancias obtenidas a partir de productos naturales $\left(^{8-11}\right)$. Dentro de ellas está el própolis o propóleo, una sustancia resinosa y pegajosa, de color verde pardo, castaño o negro, y de sabor acre, que es elaborado por la abeja Apis mellifera mediante exudados vegetales mezclados con sustancias salivales propias de las abejas y con los bálsamos procedentes del polen, cuya función en la colmena es la de sellarla herméticamente e impedir infecciones en ella ${ }^{(12,13)}$.

Al propóleo se le atribuyen propiedades antibacterianas, antivirales, antifúngicas, antioxidantes, antiinflamatorias, cicatrizantes, anestésicas, antitumorales e inmunomoduladoras $\left.{ }^{12-15}\right)$. En cuanto a su actividad antimicrobiana, 
el mecanismo de acción del propóleo es complejo y se atribuye a la sinergia entre los elementos que lo componen, como flavonoides, ácidos grasos, ácidos aromáticos, ésteres, hidroxiácidos, sesquiterpenos y otros compuestos fenólicos ${ }^{(12,15)}$. Por otra parte, es capaz de inhibir la síntesis de mediadores del proceso de inflamación, como las prostaglandinas y leucotrienos, así como de promover la actividad fagocítica $\left({ }^{13}\right)$. Igualmente, estudios sugieren que es capaz de suprimir la vía de la lipooxigenasa del ácido araquidónico $\left({ }^{14,15}\right)$.

Diversas investigaciones evidencian que el propóleo presenta características particulares de acuerdo con la ubicación geográfica de su origen, relacionadas con la flora y condiciones climáticas, lo que determina su capacidad antibacteriana y alta biocompatibilidad $\left({ }^{15,16}\right)$. En el caso de los propóleos provenientes del Perú, se ha probado que aquellos recolectados en la provincia de Oxapampa, departamento de Pasco, cumplen con estándares internacionales de calidad y evidencian mejores propiedades que los procedentes de otras zonas $\left({ }^{12}\right)$. Aun así, el potencial específico del propóleo peruano permanece falto de exploración científica. Del mismo modo, aunque la susceptibilidad de diversos géneros bacterianos frente a esta sustancia ha sido objeto de investigación, los estudios que incluyan bacterias endopatógenas son todavía limitados, así como aquellos que comparen su efecto antibacteriano con otras sustancias usadas con ese fin en el campo endodóntico.

El propósito del presente estudio fue comparar la actividad antibacteriana in vitro del extracto etanólico de propóleo de Oxapampa (Perú), en concentraciones del $20 \%$ y el $30 \%$ con el paramonoclorofenol alcanforado frente a cepas de Enterococcus faecalis ATCC 29212 y Fusobacterium nucleatum ATCC 25586.

\section{MATERIALES Y MÉTODOS}

Este estudio experimental, in vitro, fue realizado en el laboratorio de Microbiología A201, ubicado en la Facultad de Medicina Humana, en Sede Villa, a cargo de la Coordinación de Laboratorios de Ciencias Naturales de la Universidad Científica del Sur, en el periodo de setiembre a diciembre de 2017, en 30 placas Petri que contenían las cepas activadas de Enterococcus faecalis ATCC 29212 y Fusobacterium nucleatum ATCC 25586. Fue presentado para su revisión y aprobación a la Comisión de Revisión de Aspectos Metodológicos y Éticos de la carrera de Estomatología de la Universidad Científica del Sur.

Se utilizó la fórmula de comparación de medias a un nivel de confianza del $95 \%$ y con un margen de error del $5 \%$, a partir de los resultados de una prueba piloto. Esto dio como resultado 15 placas Petri para la prueba frente a Enterococcus faecalis ATCC 29212 y 15 placas Petri para la prueba frente a Fusobacterium nucleatum ATCC 25586. Los criterios de inclusión fueron las cepas bacterianas reactivadas y debidamente identificadas mediante tinción Gram, mientras que los criterios de exclusión fueron las cepas contaminadas con otras bacterias u hongos.

Las sustancias experimentales usadas fueron el extracto etanólico de propóleo (EEP) al $20 \%$ y al $30 \%$, que se comparó con el paramonoclorofenol alcanforado (PMCFA), y se usó como control positivo la clorhexidina al $2 \%$ y el agua destilada como control negativo.

Los EEP se elaboraron a partir del propóleo recolectado en su estado natural de los apiarios ubicados en la provincia peruana de Oxapampa. La recolección se llevó a cabo empleando el método técnico, que usa una parrilla de plástico y bajas temperaturas, lo que 
reduce al mínimo el contacto con potenciales contaminantes. Posteriormente, se procedió al envasado de la muestra en una bolsa atóxica, dentro de un frasco de tapa hermética y cubierto de la luz.

Para la elaboración de los extractos, el propóleo se sometió a $7^{\circ} \mathrm{C}$ por 24 horas; luego, se cortó en trozos pequeños que se extendieron sobre una mesa y se seleccionó aquellos que no presentaron impurezas, para triturarlos en un mortero de porcelana. Una vez pulverizados, se maceraron $100 \mathrm{~g}$ del polvo de propóleo obtenido en $200 \mathrm{ml}$ de etanol al $100 \%$, a $37{ }^{\circ} \mathrm{C}$, durante 8 días. Posteriormente, se filtró la solución con papel Whatman n. 60 y se la sometió al rotavapor a $40{ }^{\circ} \mathrm{C}$, para extraer el etanol. Terminado el proceso, se colocó el extracto en un frasco ámbar y se enrasó a $200 \mathrm{ml}$ con etanol al $100 \%$.

La solución obtenida se dividió en dos frascos con $100 \mathrm{ml}$ de extracto al $50 \%$ de concentración de propóleo, a los que se les agregó $150 \mathrm{ml}$ y $70 \mathrm{ml}$ de etanol al $100 \%$, respectivamente, con el fin de obtener un extracto etanólico al $20 \%$ y otro al $30 \%$ de concentración de propóleo. Todo este proceso se llevó a cabo en el Laboratorio de Investigación de Productos Naturales de la UPCH. Una vez alcanzadas las concentraciones deseadas, los extractos fueron llevados al Centro de Control Analítico de la Facultad de Farmacia y Bioquímica de la UNMSM, donde se les sometió al análisis UV-VIS, que registró una concentración de flavonoides de $11,27 \mathrm{mg} / \mathrm{ml}$ y $21,509 \mathrm{mg} / \mathrm{ml}$ para los extractos al $20 \%$ y el $30 \%$, respectivamente.

Las cepas bacterianas de Enterococcus faecalis ATCC 29212 y Fusobacterium nucleatum ATCC 25586 se retiraron las cepas del vial en el que estaban contenidas y se procedió a su activación. Mediante el hisopo del vial, se llevó las cepas hidratadas a las placas
Petri con agar previamente preparadas; luego, usando un asa de siembra esterilizada, se desplazó el inóculo en forma de estrías. En el caso de Enterococcus faecalis se utilizó el agar bilis esculina, mientras que para el Fusobacterium nucleatum se usó el agar Schaedler enriquecido con vitamina $\mathrm{K}$.

Las placas que contenían Enterococcus faecalis fueron selladas y llevadas a incubación por un periodo de 24 horas a $37^{\circ} \mathrm{C}$. Por otro lado, las placas que contenían Fusobacterium nucleatum fueron selladas y llevadas a una jarra de anaerobiosis, junto con un sobre generador y un sachet indicador de anaerobiosis, para después cerrar la jarra herméticamente, cubrirla de la luz y llevarla a la incubadora por un periodo de 7 días a $37{ }^{\circ} \mathrm{C}$ (incubadora digital de $50 \mathrm{~L}$ de capacidad, marca Shel Lab).

Luego de las 24 horas de incubación, se realizó la prueba de tinción Gram para comprobar el género bacteriano deseado, tomándose un inóculo de las colonias aisladas de Enterococcus faecalis. El mismo procedimiento se llevó a cabo con las colonias aisladas de Fusobacterium nucleatum, después de los 7 días de incubación.

Una vez activadas e identificadas, se tomó un inóculo de cada cepa con un hisopo estéril, para después sumergirlo dentro de una suspensión directa en infusión cerebro corazón (BHI) ajustada a la escala de Mc Farland 0,5. Luego, se procedió con la siembra, desplazando uniformemente el hisopo sobre el agar con movimientos en forma de estrías.

En las placas sembradas con Enterococcus faecalis, se colocaron discos de papel Whatman $n .^{\circ} 3$ estériles, previamente acondicionados a $6 \mathrm{~mm}$ de diámetro, embebidos en 60 ul de las sustancias experimentales y control. Las sustancias experimentales fueron 
un EEP al $30 \%$, un EEP al $20 \%$ y paramonoclorofenol alcanforado, mientras que las sustancias control fueron clorhexidina al $2 \%$ y agua destilada. En el caso de las placas sembradas con Fusobacterium nucleatum, los discos de papel fueron embebidos en 10 ul de las mismas sustancias experimentales y control. Una vez concluida la aplicación de los discos, se sellaron las placas y se incubaron ambas cepas a $37^{\circ} \mathrm{C}$, por un periodo de 24 horas en el caso de Enterococcus faecalis y siete días, en condiciones de anaerobiosis y cubierta de la luz, para el Fusobacterium nucleatum. Todo el procedimiento se llevó a cabo en el diámetro de $60 \mathrm{~cm}$ de un mechero Bunsen encendido y en un tiempo no mayor a 5 minutos para cada placa.

La lectura de las placas que contenían Enterococcus faecalis se realizó a las 24 y 48 horas de la incubación (figuras 1 y 2), mientras que la de las placas que contenían Fusobacterium nucleatum se realizó a los siete días de la incubación (figura 3), mediante el registro en milímetros de los halos de inhibición con un calibrador Vernier.

El investigador principal fue capacitado y calibrado en la medición de halos de inhibición. El coeficiente de correlación interclase fue de 0,985.

Se realizó el análisis estadístico mediante el programa SPSS versión 21. Se aplicó la prueba de Kruskal Wallis y Anova de un factor según la presencia de normalidad en los datos, para comparar las soluciones experimentales con el efecto antibacteriano que producen por cada periodo en función al tamaño de los halos de inhibición, mientras que, para comparar el efecto entre las soluciones experimentales, se utilizaron las pruebas U de Mann Whitney y HSD de Tukey.
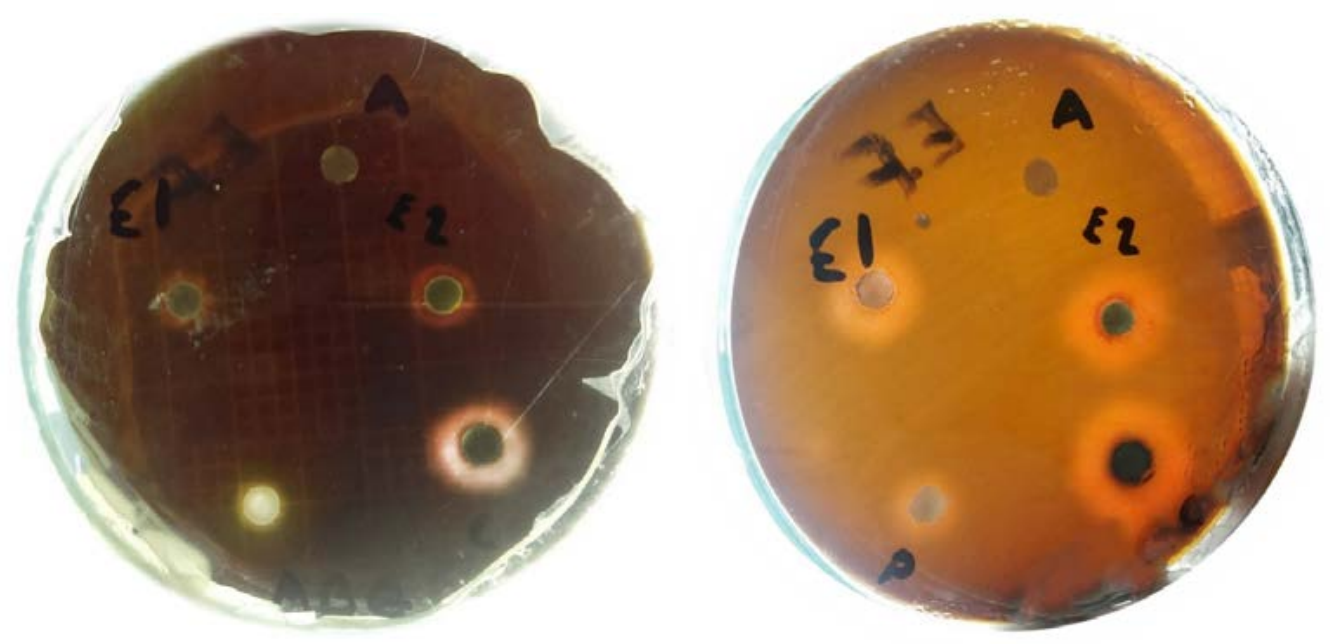

Figura 1. DERECHA: CRECIMIENTO DE haLOS DE INHIBICIÓN A LAS 24 HORAS FRENTE A E. FAECALIS. IZQUIERDA: CRECIMIENTO DE HALOS DE INHIBICIÓN A LAS 48 HORAS FRENTE A E. FAECALIS. E1: EEP 20\%. E2: EEP 30\%. P: PMCFA. C: CHX 2\%. A: AguA DESTILADA. 

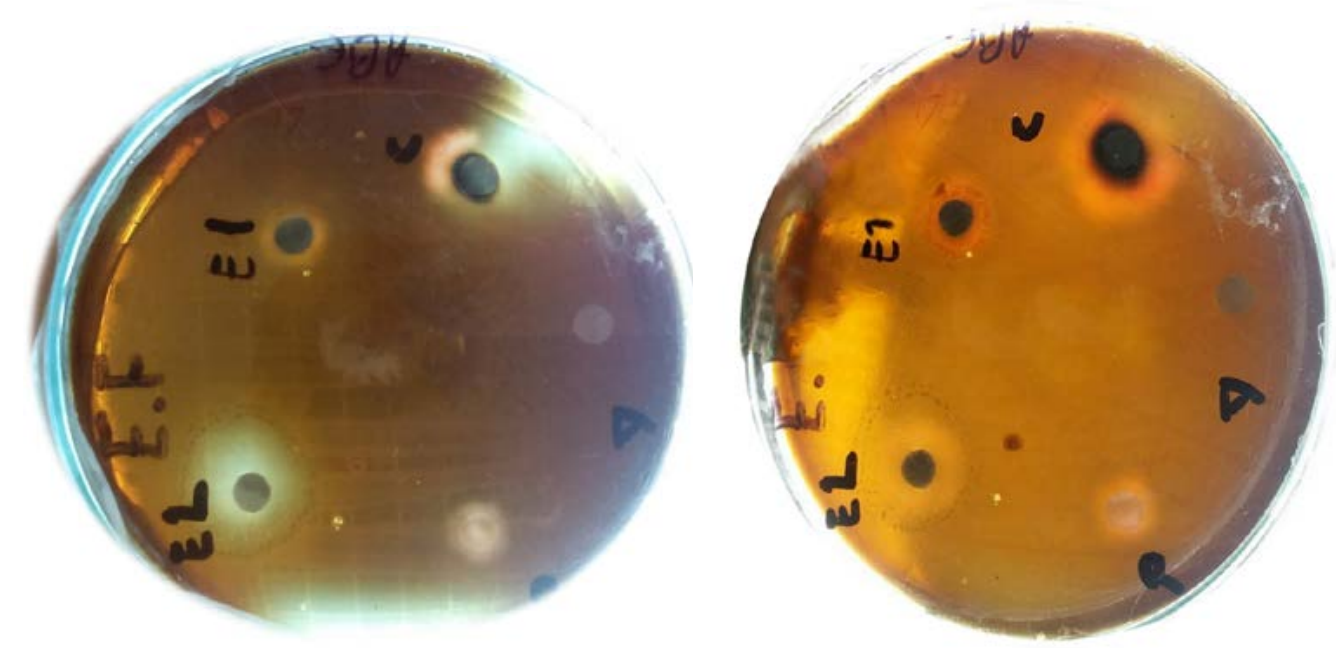

FIGURA 2. DERECHA: CRECIMIENTO DE hALOS DE INHIBICIÓN A LAS 24 HORAS FRENTE A E. FAECALIS. IZQUIERDA: CRECIMIENTO DE HALOS DE INHIBICIÓN A LAS 48 HORAS FRENTE A E. FAECALIS. E1: EEP 20\%. E2: EEP 30\%. P: PMCFA. C: CHX 2\%. A: Agua DESTILAdA.
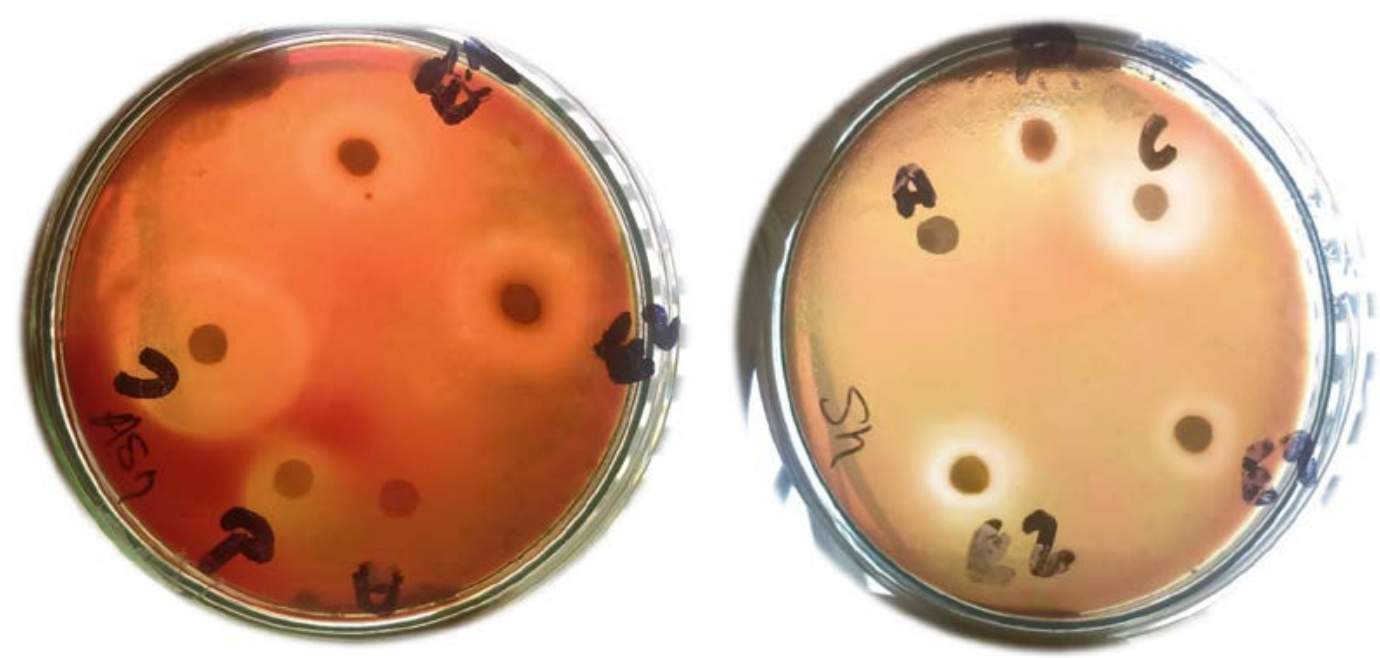

Figura 3. Crecimiento de halos de inhibición a los 7 días frente a F. nucleatum. E1: EeP 20\%. E2: EEP 30\%. P: PMCFA. C: CHX 2\%. A: Agua DESTILADA.

\section{RESULTADOS}

Pudo comprobarse el efecto antibacteriano de las sustancias experimentales sobre el Enterococcus faecalis a las 24 horas. El EEP al $30 \%$ obtuvo halos de inhibición con una media de $14,23 \mathrm{~mm}$, lo que constituye un mayor efecto antibacteriano que la concentración al $20 \%$ con halos de 10,32 mm y que el PMCFA con $9,10 \mathrm{~mm}$. Se muestra también que el PMCFA exhibió los menores halos de inhibición: $p=0,000$ (tabla 1).
Luego de 48 horas, se observó que el EEP al $30 \%$ mantuvo mayor efecto antibacteriano, con halos de $14,96 \mathrm{~mm}$, mientras que la concentración al $20 \%$ mostró halos de $11,00 \mathrm{~mm}$, lo que evidencia un ligero aumento de la actividad antibacteriana de las sustancias experimentales sobre el Enterococcus faecalis en este periodo. Asimismo, se muestra que el PMCFA exhibió los menores halos de inhibición $(8,94 \mathrm{~mm})$, acompañados de una ligera disminución de su efecto antibacteriano: $p=0,000$ (tabla 2 ). 
Se observa también el efecto antibacteriano de las sustancias experimentales sobre el Fusobacterium nucleatum a los 7 días. El EEP al $30 \%$ mostró halos de inhibición con una media de 23,17 mm y el EEP al $20 \%$ halos de $18,89 \mathrm{~mm}$, lo que indica mayor efecto antibacteriano para la concentración al $30 \%$. Asimismo, se muestra que el PMCFA exhibió el menor efecto antibacteriano, con halos de 13, $50 \mathrm{~mm}$ y $\mathrm{p}=0,000$ (tabla 3 ).

Al comparar las medias de cada una de las sustancias experimentales, se halló que los halos de inhibición del extracto etanólico de propóleo al 30\% fueron los mayores de entre todas las sustancias experimentales, seguidos por la concentración al $20 \%$ y por el PMCFA, tanto frente a Enterococcus faecalis a las 48 horas como a Fusobacterium nucleatum a los 7 días. Se encontraron diferencias estadísticamente significativas en la comparación múltiple entre las sustancias experimentales, con un $p<0,005$, mediante la prueba HSD de Tukey (tabla 4).

Igualmente, al comparar las medias de cada una de las sustancias experimentales frente a Enterococcus faecalis a las 24 horas, se halló que los halos de inhibición del EEP al $30 \%$ fueron los mayores de entre todas las sustancias experimentales, seguidos por la concentración al $20 \%$ y por el PMCFA. Se encontraron diferencias estadísticamente significativas en la comparación múltiple entre las sustancias experimentales, con un $p$ $<0,005$, mediante la prueba $U$ de MannWhitney (tabla 5).

TABLA 1. Comparación de los VALORES DEL EFECTO ANTIBACTERIANO DE LAS SUSTANCIAS EXPERIMENTALES FRENTE AL ENTEROCOCCUS FAECALIS A LAS 24 HORAS

\begin{tabular}{|l|c|c|c|}
\hline Sustancias experimentales & $n{ }^{\circ}$ & Media & P \\
\hline Extracto de propóleo 20\% & 15 & 10,32 & \\
\hline Extracto de propóleo 30\% & 15 & 14,23 & $<0,001$ \\
\hline PMCFA & 15 & 9,10 & \\
\hline
\end{tabular}

${ }^{*}$ Nivel de significancia $p \leq 0,05$

Prueba de Kruskal-Wallis

Fuente: Elaboración propia

TABla 2. Comparación de los VAlORES DEL EFECTO ANTIBACTERIANO DE LAS SUSTANCIAS EXPERIMENTALES FRENTE AL ENTEROCOCCUS FAECALIS A LAS 48 HORAS

\begin{tabular}{|l|c|c|c|}
\hline Sustancias experimentales & $n{ }^{\circ}$ & Media & P \\
\hline Extracto de propóleo $20 \%$ & 15 & 11,00 & \\
\hline Extracto de propóleo $30 \%$ & 15 & 14,96 & \multirow{2}{*}{$<0,001^{*}$} \\
\hline PMCFA & 15 & 8,94 & \\
\hline
\end{tabular}

*Nivel de significancia $p \leq 0,05$

Prueba de Anova de un factor

TABLA 3. COMPARACIÓN DE LOS VALORES DEL EFECTO ANTIBACTERIANO DE LAS SUSTANCIAS EXPERIMENTALES FRENTE AL FUSOBACTERIUM NUCLEATUM A LOS 7 DÍAS

\begin{tabular}{|l|l|l|c|}
\hline Sustancias experimentales & $\mathrm{n}^{\circ}$ & Media & $\mathrm{P}$ \\
\hline Extracto de propóleo $20 \%$ & 15 & 18,89 & \\
\hline Extracto de propóleo $30 \%$ & 15 & 23,17 & $<0,001^{*}$ \\
\hline PMCFA & 15 & 13,50 & \\
\hline
\end{tabular}

*Nivel de significancia $p \leq 0,05$

Prueba de Anova de un factor

Fuente: Elaboración propia 
TABLA 4. Comparación MÚLTIPLE ENTRE LOS VALORES DEL EFECTO ANTIBACTERIANO DE LAS SUSTANCIAS EXPERIMENTALES QUE MOSTRARON DISTRIBUCIÓN NORMAL

\begin{tabular}{l|l|l|c|c|}
\hline $\begin{array}{l}\text { Microorganismos y tiempo } \\
\text { de prueba }\end{array}$ & \multicolumn{2}{|c|}{ Sustancias experimentales } & $\begin{array}{c}\text { Diferencia } \\
\text { de medias }\end{array}$ & P \\
\hline $\begin{array}{l}\text { Efecto antibacteriano de las } \\
\text { sustancias experimentales } \\
\text { frente al Enterococcus } \\
\text { faecalis a las 48 horas }\end{array}$ & $\begin{array}{l}\text { Extracto etanólico } \\
\text { de propóleo 20\% }\end{array}$ & $\begin{array}{l}\text { Extracto etanólico } \\
\text { de propóleo 30\% }\end{array}$ & $-3,95$ & $<0,001^{*}$ \\
\hline $\begin{array}{l}\text { Extracto etanólico } \\
\text { de propóleo 30\% }\end{array}$ & PMCFA & 2,07 & $<0,001^{*}$ \\
\hline $\begin{array}{l}\text { Eustancias experimentales } \\
\text { frente a Fusobacterium } \\
\text { nucleatum a los 7 días }\end{array}$ & $\begin{array}{l}\text { Extracto etanólico } \\
\text { de propóleo 20\% }\end{array}$ & $\begin{array}{c}\text { Extracto etanólico } \\
\text { de propóleo 30\% }\end{array}$ & $-4,28$ & $<0,001^{*}$ \\
\hline $\begin{array}{l}\text { Extracto etanólico } \\
\text { de propóleo 30\% }\end{array}$ & PMCFA & 5,39 & $<0,001^{*}$ \\
\hline $\begin{array}{l}\text { *La diferencia de medias es significativa en el nivel 0,05 } \\
\text { Prueba HSD de Tukey } \\
\text { Fuente: Elaboración propia }\end{array}$ & & & 9,67 & $<0,001^{*}$ \\
\hline
\end{tabular}

TABla 5. CoMparación MÚLTIPLE ENTRE LOS VALORES DEL EFECTO ANTIBACTERIANO DE LAS SUSTANCIAS EXPERIMENTALES QUE NO MOSTRARON DISTRIBUCIÓN NORMAL

\begin{tabular}{|l|c|c|c|c|c|}
\hline Microorganismos y tiempo de prueba & Sustancias experimentales & n. & Media & DE & P \\
\hline $\begin{array}{l}\text { Efecto antibacteriano de las } \\
\text { sustancias experimentales frente } \\
\text { al Enterococcus faecalis a las 24 }\end{array}$ & Extracto de propóleo 20\% & 15 & 10,32 & 1,101 & $<0,001^{*}$ \\
\hline horas & Extracto de propóleo 30\% & 15 & 14,23 & 1,099 & \\
\hline & Extracto de propóleo 20\% & 15 & 10,32 & 1,101 & 0,006 \\
\hline & PMCFA & 15 & 9,10 & 0,806 & \\
\hline & PMCFA & 15 & 9,10 & 0,806 & \\
\hline
\end{tabular}

*Nivel de significancia $p \leq 0,05$

Prueba de U de Mann-Whitney

Fuente: Elaboración propia

\section{DISCUSIÓN}

El presente estudio compara la actividad antibacteriana in vitro de un extracto etanólico elaborados a partir de propóleo proveniente de la provincia peruana de Oxapampa, a concentraciones del $20 \%$ y el $30 \%$, con el paramonoclorofenol alcanforado (PMCFA) sobre cepas activadas de Enterococcus faecalis ATCC 29212 y Fusobacterium nucleatum ATCC 25586.

Se ha comprobado que las propiedades y calidad del propóleo varían según la zona de procedencia $\left({ }^{12,15,16}\right)$. Rodríguez $\left({ }^{17}\right)$ evaluó la actividad antibacteriana de cuatro EEP, elaborados a partir de muestras recolectadas en el departamento de Lambayeque. El promedio del diámetro de los halos de inhibición en su estudio fue menor que lo obtenido en el estudio conducido por Díaz y Proaño (11), usando un EEP proveniente de Oxapampa a la misma concentración y la misma cepa bacteriana. De igual manera, Arévalo $\left({ }^{18}\right)$ obtuvo diferentes resultados entre sus variables, al probar el efecto antibacteriano de propóleos provenientes de La Libertad, San Martín y Ayacucho frente a Streptococcus mutans, lo que es contrastable con lo observado por Jara $\left({ }^{19}\right)$, que obtuvo halos superiores para un EEP procedente de Oxapampa, frente a la misma cepa. Asimismo, Álvarez $\left.{ }^{(20}\right)$ 
probó extractos etanólicos elaborados a partir de propóleo recolectado en la provincia de Huaraz, frente a Enterococcus faecalis por 24 horas, y obtuvo halos menores en promedio que los obtenidos en el presente estudio. Estas investigaciones corroboran la variabilidad de las propiedades del propóleo según su procedencia y sugieren que el proveniente de Oxapampa posee un efecto antibacteriano superior frente a bacterias de importante patogenicidad odontológica.

En relación con la actividad antibacteriana del propóleo, esta ha sido evaluada frente a distintas cepas como el Enterococcus faecalis $\left({ }^{11}, 21\right)$, microorganismo de alta prevalencia en la infección endodóntica secundaria y necrosis pulpar $\left.{ }^{(5-7}\right)$. En ese sentido, Pimenta y cols. $\left({ }^{9}\right)$ mostraron que un EEP brasileño tuvo una tasa significativa de reducción de crecimiento bacteriano frente a Enterococcus faecalis, resultado similar al obtenido por Moncla y cols. $\left.{ }^{22}\right)$. Por su parte, Bhandari y cols. $\left({ }^{23}\right)$, encontraron mayor actividad antibacteriana por parte del propóleo indio que el hidróxido de calcio frente al Enterococcus faecalis, al igual que Saha y cols $\left({ }^{24}\right)$. En tanto, estudios nacionales corroboran las propiedades antibacterianas del propóleo, como lo hallado por Álvarez $\left({ }^{20}\right)$, que probó EEP proveniente de la provincia de Huaraz, frente a Enterococcus faecalis por 24 horas, y obtuvo halos de $8,56 \mathrm{~mm}$ y 11,63 $\mathrm{mm}$ en promedio, para concentraciones del $25 \%$ y el $75 \%$, respectivamente. Esto es consistente con el presente estudio, en el que se obtuvieron halos de 10,32 $\mathrm{mm}$ para la concentración del $20 \%$ y de $14,23 \mathrm{~mm}$ para la del $30 \%$, frente a las cepas de Enterococcus faecalis luego de 24 horas de incubación. Los resultados de estas investigaciones demuestran el potencial antibacteriano del propóleo frente al Enterococcus faecalis y fortalecen la evidencia en cuanto a la superioridad del proveniente de Oxapampa dentro del ámbito nacional.

Otra especie bacteriana muy presente en las infecciones endodónticas es Fusobacterium nucleatum $\left(^{4-7}\right)$, cuya importante capacidad de coagregación ha llevado a que se le adjudique un rol protagónico en el desarrollo del biofilm dentro del sistema de conductos radiculares $(3,4,5)$. En el presente estudio se obtuvieron halos de $18,89 \mathrm{~mm}$ para la concentración del $20 \%$ y 23,17 mm para la del $30 \%$, frente a las cepas de F. nucleatum luego de 7 días de incubación. Esto coincide con lo mostrado por Boyanova y cols. $\left({ }^{25}\right)$, que obtuvieron halos de $10,4 \mathrm{~mm}$ para un extracto al $30 \%$ por un periodo de tres días al probar un EEP búlgaro frente a la misma cepa. Por su parte, el estudio de De Paula y cols. $\left({ }^{26}\right)$ evidenció halos de 15,26 mm en promedio, luego de 5 días de incubación, lo que sugiere un aumento de la capacidad antibacteriana correlativa al tiempo de incubación. Asimismo, Packia Lekshmi y cols. $\left({ }^{10}\right)$ obtuvieron halos de $27,33 \mathrm{~mm}$ para un EEP de la India, al $100 \%$, a las 24 horas; mientras que Díaz y Proaño $\left({ }^{11}\right)$, al evaluar tres EEP proveniente de Oxapampa frente a $F$. nucleatum, registraron halos de 11,96 $\mathrm{mm}, 17,06 \mathrm{~mm}$ y $18 \mathrm{~mm}$ para concentraciones al $1 \%, 5 \%$ y $10 \%$, respectivamente. Los resultados de la presente investigación, al compararlos con estos estudios, demuestran que el potencial antibacteriano del propóleo frente al F. nucleatum varía en forma directamente proporcional a la concentración del EEP y el tiempo de incubación.

Diversas investigaciones han sugerido que los extractos etanólicos de propóleo manifiestan su máxima capacidad antibacteriana a corto plazo $\left({ }^{18,19}\right)$. En el presente estudio no se obtuvo una diferencia significativa al comparar el efecto de los extractos a las 24 y 48 horas frente 
a Enterococcus faecalis, lo que contrasta con los resultados mostrados por Arévalo, que evidencian un aumento significativo en dos de sus soluciones experimentales a las 48 horas $\left({ }^{18}\right)$. De igual modo, Madhubala y cols. ${ }^{(21}$ ) observaron que el propóleo canadiense alcanzó el índice máximo de reducción de colonias bacterianas a las 48 horas y lo mantuvo a los 7 días, frente a cepas de Enterococcus faecalis. Por su parte, Bhandari y cols. $\left.{ }^{(23}\right)$ no hallaron diferencia significativa en el efecto antibacteriano de un gel a base de propóleo indio al primer, tercer y quinto día, frente a Enterococcus faecalis; al igual que Kayaoglu y cols., $\left({ }^{27}\right)$ que no hallaron diferencia significativa entre el efecto antibacteriano a las 24 y 48 horas de dos EEP turco frente a Enterococcus faecalis, pero sí luego de 7 días de incubación, lo que concuerda con los resultados del presente estudio. Puede atribuirse la variabilidad de la capacidad antibacteriana en el tiempo a la procedencia del propóleo o al vehículo usado; asimismo, en el presente estudio los halos mayores se evidenciaron frente a Fusobacterium nucleatum, cuyo periodo de incubación fue de 7 días, lo que sugiere un comportamiento de liberación paulatina de elementos activos por parte del EEP proveniente de Oxapampa.

Con relación a sus propiedades, se ha establecido que la capacidad antibacteriana del propóleo radica principalmente en la presencia de flavonoides en su composición $\left({ }^{12,14-16}\right)$. Kayaoglu y cols. ${ }^{27}$ ) encontraron una diferencia significativa entre dos tipos de EEP, de los cuales aquel que presentó un mayor efecto antibacteriano fue el que contenía mayor porcentaje de flavonoides, según el análisis GC-MS. Por su parte, Reyes ${ }^{(28)}$ registró $7,35 \mathrm{mg} / \mathrm{ml}$ como contenido total de flavonoides y halos de 16,73 $\mathrm{mm}$ para una tintura de propóleo comercial proveniente de Oxapampa contra patógenos periodontales. De acuerdo con la presente investigación, según el análisis UV-VIS, los EEP al 20\% y al 30\% registraron una concentración de flavonoides de $11,27 \mathrm{mg} / \mathrm{ml}$ y $21,509 \mathrm{mg} / \mathrm{ml}$, respectivamente, y fue el EEP al $30 \%$ el que evidenció un mayor efecto antibacteriano. Esto concuerda con las investigaciones que asocian una mayor presencia de flavonoides con la efectividad antibacteriana.

En cuanto a la comparación con la clorhexidina, los resultados del presente estudio muestran que, a una concentración del $2 \%$, la clorhexidina exhibe halos superiores a todas las sustancias probadas, hecho que también es evidenciado por las investigaciones que la usan como control positivo $(18,20,23)$. Sin embargo, estos resultados se limitan al ambiente in vitro y frente a bacterias planctónicas, lo cual puede contrastarse con lo hallado con Akca y cols. $\left({ }^{12}\right)$, Mohammadi y Abbott $\left({ }^{29}\right)$, y Spratt y cols. $\left({ }^{30}\right)$, que sugieren una actividad significativamente menor de la clorhexidina sobre biofilms endodónticos.

\section{CONCLUSIONES}

El presente estudio evidenció que un extracto etanólico elaborado a partir de propóleo de Oxapampa mostró efecto antibacteriano a una concentración del $20 \%$ y el $30 \%$, contra las cepas activadas de Enterococcus faecalis ATCC: 29212 y Fusobacterium nucleatum ATCC: 25586. Frente a ambas cepas, el extracto al $30 \%$ mostró mayor efecto antibacteriano. Asimismo, se encontró que de las 24 a 48 horas hubo un incremento leve en el efecto antibacteriano de los extractos a ambas concentraciones, lo que indica una lenta capacidad de libración de metabolitos activos y que alcanza mayores concentraciones a los siete días. 
En cuanto a la comparación de su capacidad antibacteriana con el PMCFA, los extractos al $30 \%$ y el $20 \%$ mostraron un efecto antibacteriano significativamente mayor que el PMCFA frente a cepas activadas de Enterococcus faecalis y Fusobacterium nucleatum.

Contribución del autor: José Diego Torres Mantilla ha participado en la concepción del artículo, la recolección de información, su redacción y la aprobación de la versión final.

Fuente de financiamiento: Autofinanciado

Conflictos de interés: El autor declara no tener conflictos de interés de ningún tipo.

\section{REFERENCIAS BIBLIOGRÁFICAS}

1. Garzón I, Sorbera L. Complejo dentino-pulpar: pulpa dental. En: Histología, embriología e ingeniería tisular bucodental. $3 .^{a}$ ed. Ciudad de México: Editorial Médica Panamericana; 2009.

2. Canalda C, Brau E. Endodoncia Técnicas Clínicas y Bases Científicas. 3. ${ }^{a}$ ed. Barcelona: Elsevier; 2006.

3. Hargreaves K, Berman L, Cohen S. Cohen. Vías de la pulpa. 10. ${ }^{a}$ ed. Barcelona: Elsevier; 2011.

4. Torabinejad M, Walton R. Endodoncia: principios y práctica. $4{ }^{a}$ ed. Barcelona: Elsevier; 2010.

5. Pérez R, Díaz-Flores V, Algar J, Valencia O, Estévez R, Cisneros R. Actualización en microbiología endodóntica. Cient. Dent. 2013; 10 (1): 27-39.

6. Andrade V, Dos Santos R, de Lima R, Netto K, Guimarães L, Coplle L. Microorganisms involved in endodontic infection of permanent teeth: A systematic review. Afr. J. Microbiol. Res. 2013; 7 (18): 1819-26.

7. Galhotra V, Dey S, Priyank H, Paranjape T, Sharma N, Singh I. Prevalence of microorganisms in root canals of human permanent teeth with symptomatic nonvital pulp and chronic periapical lesions: a microbiological study. J Int Oral Health. 2015; 7 (11): 71-4.

8. Akca A, Akca G, Topçu F, Macit E, Pikdöken L, Özgen I. The comparative evaluation of the antimicrobial effect of propolis with Clorhexidine against oral pathogens: an in vitro study. BioMed Research Int. 2016; (3): 1-8. 
9. Pimenta $\mathrm{H}$, Violante I, Musis $\mathrm{C}$, Borges A, Aranha A. In vitro efectiness of Brazilian brown propolis against Enterococcus faecalis. Braz Oral Res. 2015; 29 (1): 1-6.

10. Packia Lekshmi N, Viveka S, Sowmia N, Jeeva S, Raja Brindha J. Antimicrobial activity of propolis against dental pathogens. AARJSH. 2013; 1 (18): 402-14.

11. Días J, Proaño D. Actividad antibacteriana in vitro del extracto etanólico de propóleo de Oxapampa Perú, sobre cepas de Porphyromonas gingivalis y Fusobacterium nucleatum. Rev. Etomatol. Herediana. 2011; 21 (3): 125-30.

12. López del Villar J, Ubillús M. Estandarización del propóleos de la provincia de Oxapampa, departamento de Pasco (Perú) como materia prima para su utilización a nivel industrial. [Tesis de grado]. Lima: Universidad Nacional Mayor de San Marcos; 2004.

13. Vargas RD, Torrescano G, Mendoza A, Vallejo B, Acedo E, Sánchez J, y cols. Mecanismos involucrados en la actividad antioxidante y antibacteriana del propóleos. Biotecnia. 2014; 16 (1): 32-7.

14. Rossi A, Ligresti A, Longo R, Russo A, Borrelli F, Sautebin L. The inhibitory effect of propolis and caffeic acid phenethyl ester on cyclooxygenase activity in $\mathrm{J} 774$ macrophages. Phytomedicine. 2002; 9 (6): 530-5.

15. Mayta F, Sacsaquispe S, Ceccarelli J, Alania J. Propóleo peruano: una nueva alternativa terapéutica antimicrobiana en estomatología. Rev Estomatol Hered. 2012; 22 (1): 50-8.

16. Cheng H, Qin ZH, Guo XF, Hu XS, Wu JH. Geographical origin identification of propolis using GC-MS and electronic nose combined with principal component analysis. Food Rest. Int. 2013; 51 (1): 813-22.

17. Rodríguez M. Actividad antibacteriana de cuatro soluciones del extracto de propóleo en bacterias anaerobias frecuentes en necrosis pulpar con reacción periapical. [Tesis de grado]. Lima: Universidad Nacional Mayor de San Marcos. 2007.

18. Arévalo CM. Efecto antibacteriano in vitro de tres variedades de própolis frente a Streptococcus mutans ATCC 25175. [Tesis de grado]. Trujillo: Universidad Peruana Antenor Orrego; 2007.

19. Jara R. Evaluación in vitro del efecto antibacteriano de cinco propóleos peruanos sobre cepas de Streptococcus mutans (ATCC 25175) y Streptococcus sanguinis (ATCC 10556) [Tesis de grado]. Lima: Universidad Peruana de Ciencias Aplicadas; 2014.

20. Álvarez M. Efecto antibacteriano in vitro del extracto etanólico de propolis de Apis mellifera (propóleo) frente a Enterococcus faecalis ATCC 29212. [Tesis de grado]. Trujillo: Universidad Privada Antenor Orrego; 2014.

21. Madhubala M, Srinivasan N, Abamed S. Comparative evaluation of Propolis and Triantibiotic Mixture as an intracanal medicament against Enterococcus Faecalis. JOE. 2011; 37 (9): 1287-9. 
22. Moncla B, Guevara P, Wallace J, Marcucci M, Nor J, Bretz W. The inhibitory activity of typified propolis against Enterococcus species. ZNC. 2012; 67 (5-6): 249-56.

23. Bhandari S, Ashwini T, Chetan R. An in vitro evaluation of antimicrobial efficacy of $2 \%$ Chlorhexidine gel, propolis, and calcium hydroxide against Enterococcus Faecalis in human root dentin. JCDR. 2014; 8 (11): 60-3.

24. Saha S, Nair R, Asrani H. Comparative evaluation of propolis, metronidazole with clorhexidine, calcium hydroxide and Curcuma longa extract as intracanal medicament against E. Faecalis-an in vitro study. JCDR. 2015; 9 (11): 19-21.

25. Boyanova L, Kolarov R, Gergova G, Mitov I. In vitro activity of Bulgarian propolis against 94 clinical isolates of anaerobic bacteria. Anaerobe 2006; 12 (4): 173-7.

26. De Paula A, Gomes R, Santiago W, Dias R, Cortes M, Santos. Susceptibility of oral pathogenic bacteria and fungi to brazilian green propolis extract. Pharmacologyonline. 2006; 3: 467-73.

27. Kayaoglu G, Ömürlü H, Akca G, Gürel M, Gençay Ö, Sorkun K, Salih B. Antibacterial activity of Propolis versus conventional endodontic disinfectants against Enterococcus faecalis in infected dentinal tubules. J Endod. 2011; 37 (3): 376-81.

28. Reyes C. Actividad antibacteriana in vitro del extracto etanólico de propóleo peruano sobre cultivos de bacterias anaerobias frecuentes en pacientes con periodontitis crónica [Tesis de grado]. Lima: Universidad Nacional Mayor de San Marcos; 2010.

29. Mohammadi Z, Abbott PV. The properties and applications of chlorhexidine in endodontics. International Endodontic J. 2009; 42, 288-302.

30. Spratt DA, Pratten J, Wilson M, Gulabivala K. An in vitro evaluation of the antimicrobial efficacy of irrigants on biofilms of root canal isolates. International Endodontic J. 2001; 34, 300-7. 